\title{
Comparative antiplatelet activity of COX1 NSAIDS versus aspirin, encompassing regimen simplification and gastroprotection: a call for a controlled study
}

\section{Confronto fra l'attività anti-piastrinica dei FANS anti-COX1 verso l'aspirina, tenendo conto di un sistema terapeutico semplificato e della gastroprotezione. Evidenze sulla necessità di uno studio controllato}

\author{
B. Rothschild \\ Arthritis Center of Northeast Ohio and Northeastern Ohio Universities College of Medicine, \\ 5500 Market Street, Youngstown, Ohio 44512, USA; Northeastern Ohio Universities College of Medicine, Rootstown, OH; \\ 44272 Carnegie Museum of Natural History, Pittsburgh, PA 15213; and University of Kansas Museum of Natural, Lawrence, KS 66045
}

\section{RIASSUNTO}

Questo studio è stato condotto per valutare la possibilità di sostituire l'aspirina con FANS anti-COX-1 nella terapia antiaggregante di prevenzione. Non sono state osservate differenze nell'inibizione dell'aggregazione piastrinica tra aspirina, naprossene, ketoprofene o diclofenac e misoprostol (Arthrotec).

Dato che i FANS anti-COX-1 si sono dimostrati equivalenti all'aspirina in termini di efficacia di inibizione piastrini$c a, i$ regimi terapeutici possono essere semplificati nei soggetti che già assumono FANS per altre patologie. Inoltre, nonostante la sua breve emivita, l'Arthrotec si è dimostrato un efficace agente antipiastrinico. Si sottolinea, pertanto, l'opportunità di condurre studi clinici in doppio cieco per valutare l'efficacia anche in termini di prevenzione degli eventi clinici (sia cardiovascolari che gastrointestinali).

Reumatismo, 2004; 56(2):89-93

\section{INTRODUCTION}

The he cardioprotective/platelet inhibitory role of non-steroidal antiinflammatory drugs (NSAIDs) has been controversial, perhaps in contrast to the accepted prophylactic role of aspirin (114). That cardioprotective effect is attributed to the platelet aggregation inhibitory effects of aspirin and COX 1 active NSAIDS $(10,11,13)$ and can be studied without requirement for massive numbers of patients. Such cardioprotection, however, has its own risks. Significant gastrointestinal toxicity is still present with the 75-81 mg aspirin dose and appears no less than that found with the higher doses once routinely utilized in treatment of arthritis $(2,8,9)$. One study even reported that $4 \%$ of pa-

Indirizzo per la corrispondenza:

B. M. Rothschild

Arthritis center of Northeast Ohio

5500 Market Street, Youngstown, Ohio 44512, USA

E-mail: bmr@neoucom.edu tients receiving aspirin had moderate to severe bleeding (14). The challenge with aspirin is that even with a $75 \mathrm{mg}$ dose, the frequency of severe gastrointestinal hemorrhage is double that of placebo $(2,8,9)$ and not different from that observed with COX 1 NSAIDs, in the absence of gastroprotection (e.g., misoprostol) (15).

Independent of the issue of relative safety of aspirin and COX 1 NSAIDs is that of medication regimen complexity. Polypharmacy is characteristic of the older patient (16). Given the inverse relationships of compliance and medication regimen complexity (17), any reduction in that complexity should be helpful. Reducing the required medication complexity could be accomplished if treatment of arthritis (or other NSAID indications) could also fulfill anti platelet/cardioprotective requirements. As NSAIDs have largely replaced aspirin in arthritis treatment, can they replace aspirin in the cardioprotective or at least platelet inhibition application? While the COX 2 selective agent rofecoxib (Vioxx) appears to uniquely increase cardiac risk 
(18), there is no reason to expect cardioprotection from a COX 2 selective agent. COX 1 activity is required for platelet action (7). Obviously, the question of efficacy of anti platelet effect is limited to COX 1 active agents.

The question therefore is efficacy. Several studies have suggested lack of benefit of NSAIDs as cardioprotective agents and that one (ibuprofen) even counteracts the cardioprotective effect of aspirin $(3,6,7)$. However, the negative studies $(3,6)$ were seriously flawed, retrospective studies of prescription databases $(19)$. They $(3,6)$ did not examine actual NSAID usage in the intracritical period, compliance with prescribed use, failed to consider over the counter aspirin-containing drug use and were heavily weighted towards ibuprofen usage (19). This contrasts with well controlled studies which documented the cardioprotective efficacy of naproxen, flurbiprofen and diclofenac $(10,11,13$, 20 ). Laboratory studies confirm this perspective. Ketoprofen effect on platelet function, measured by arachidonic acid induction of aggregation was equivalent to $325 \mathrm{mg}$ aspirin (21).

Naproxen, flurbiprofen, ketoprofen and diclofenac have proven excellent arthritis treatment modalities, but share gastrointestinal toxicity with all COX 1 agents $(22,23)$. One approach to reducing gastrointestinal toxicity of COX 1 active agents is the gastroprotection achieved by prior ingestion of misoprostol (15). This was refined by the combination product, Arthrotec. The latter coats diclofenac with gastrointestinalprotective misoprostol (24), simplifying the medication regimen. The misoprostol is released upon ingestion, prophylactically preparing the gastrointestinal protective tract for the NSAID.

As no study documents any differential cardioprotective efficacy of naproxen over voltaren $(3,6,10$, 11) and the gastrointestinal toxicity of Arthrotec is substantially less than that of naproxen (ingested without misoprostol preparation) (24), it seemed reasonable to examine the comparative platelet aggregation inhibitory effects of those agents.

\section{METHODS}

The study population consisted of 100 consecutive patients presenting to an arthritis centre, who had been diagnosed with one specific anti-platelet treatment indication: Presence of a circulating anticoagulant. The latter was recognized in the presence of anticardiolipin or anti-Beta-2-Glycoprotein I an- tibodies $(25,26)$. While platelet aggregation was prospectively evaluated, this was not a controlled study. Arthrotec $(50 \mathrm{mg} /$ day $)$ was prescribed for those with known gastrointestinal risk factors (e.g., age, previous ulcer) (27). Individuals without risk factors were prescribed naproxen $(250 / 1000$ $\mathrm{mg}$ /day) or ketoprofen $(50 / 200 \mathrm{mg} /$ day $)$, if they had an associated arthritis requiring NSAID treatment (dosage dependent upon arthritis treatment requirement) or aspirin $(81 \mathrm{mg} /$ day $)$, if the only indication was prevention of complications related to the documented circulating anticoagulant. Those 15 individuals who had already been previously placed on 81-875 $\mathrm{mg}$ daily doses of aspirin, for cardioprotection by their primary care physicians, were maintained at those doses.

The number (variety) of ingested medications (not number of pills) ingested was recorded.

The effect of aspirin and NSAIDs and possibility of immunoglobulin class (G, M or A) and antibody variety (cardiolipin or Beta-2-GPI) effect on platelet aggregation inhibition efficacy was examined by $t$ test.

Blood was drawn 14-18 hours after the last NSAID or aspirin dose with a butterfly needle and multiple syringes and immediately placed into plastic tubes containing citrate anticoagulant (nine parts blood to one part anticoagulant) and mixed. Platelet rich plasma and platelet poor plasma were prepared by standardization with platelet count adjusted to 350,000 (28). Aliquots were incubated at 37 degrees for one minute before addition of aggregating agent: $500 \mu \mathrm{M}$ arachidonic acid, $5 \mu \mathrm{M}$ adenosine diphosphate, $0.8 \mu \mathrm{g} / \mathrm{ml}$ collagen. Aggregation was monitored for 8 minutes at 37 degrees with $1,000 \mathrm{rpm}$ stirring following aggregating agent addition.

Platelet function was considered adequately suppressed if either ADP-induced platelet aggregation was reduced $80 \%$ from baseline, collagen-induced aggregation was reduced $90 \%$ or arachidonic acid induced aggregation was completely inhibited after one week of NSAID or aspirin therapy $(1,28)$. Individuals with inadequate response to NSAID (5 individuals) had repeat testing one week after initiation of $325 \mathrm{mg}$ daily aspirin doses.

\section{RESULTS}

Average age of study population was 55 with women representing $60 \%$. The majority had fibromyalgia, osteoarthritis and inflammatory arthri- 
Table I

\begin{tabular}{|c|c|c|c|c|c|c|c|c|c|c|c|}
\hline \multirow[b]{2}{*}{ Agent } & \multirow[b]{2}{*}{$\#$} & \multicolumn{3}{|c|}{$A D P$} & \multicolumn{4}{|c|}{$\begin{array}{c}\text { Inhibition activity } \\
\text { Collagen }\end{array}$} & \multicolumn{3}{|c|}{ Arachidonic acid } \\
\hline & & Mean & $80 \% *$ & $90 \% *$ & Mean & $50 \% *$ & $80 \% *$ & $90 \% *$ & Mean & $80 \% *$ & $90 \% *$ \\
\hline Aspirin & 36 & 82 & 86 & 38 & 76 & 20 & 7 & 0 & 44 & 38 & 7 \\
\hline Arthrotec & 39 & 81 & 89 & 56 & 87 & 33 & 33 & 0 & 54 & 20 & 5 \\
\hline Keto/Nap ${ }^{\circ}$ & 25 & 80 & 95 & 67 & 65 & 32 & 32 & 0 & 70 & 25 & 0 \\
\hline $\begin{array}{l}\text { - Ketoprofen } \\
* \text { Percent of }\end{array}$ & $\begin{array}{l}\text { en } \\
\text { als }\end{array}$ & g crite & & & & & & & & & \\
\hline
\end{tabular}

tis (i.e., spondyloarthropathy, rheumatoid arthritis, calcium pyrophosphate deposition disease). Five individuals had systemic lupus erythematosus.

Total inhibition of platelet function was not observed. ADP induced platelet aggregation was suppressed by $80 \%$ in only $86 \%$ of individuals receíving aspirin, independent of doses ranging from 81 to $875 \mathrm{mg}$ (Table I). This contrasted with limited inhibition of arachidonic acid induced aggregation and minimal interference with collagen induced platelet aggregation (Table I). NSAIDs produced satisfactory inhibition of ADP-induced platelet aggregation in 93\%, collagen-induced in $33 \%$ and arachidonic acid-induced in $22 \%$, independent of agent (ketoprofen, Naproxen or Arthrotec) used. Results did not vary with presence of anticardiolipin or anti-Beta-2-Glycoprotein I antibodies or with antibody class. Collagen and arachidonic acid inhibition criteria for adequacy of platelet function inhibition were not met for either aspirin or NSAIDs.

Addition of aspirin to the NSAID regimen augmented platelet function inhibition in only one of five individuals.

The median number of ingested medications was 6.5 , ranging from 1 to 14 .

\section{DISCUSSION}

No significant difference was found between aspirin and NSAIDs in their effect on platelet function. Efficacy, as measured by $80 \%$ inhibition of ADP-induced platelet aggregation, was acceptable in $89 \%$, independent of agent. Arthrotec performed equally as well as other NSAIDs and aspirin.

To the extent that these agents affect platelet function, they are equivalent. In spite of a relatively short 75 minute serum half life (29), the voltaren component's platelet effects are no less than those of longer active NSAIDs (ketoprofen half life = 1.43 hours; Naproxen half life $=12-15$ hours) (29). Thus, the NSAID binding effect on the platelet is substantially greater than plasma half lives. While NSAIDs are reversible platelet inhibitors, their rate of dissociation from platelets appears to be sufficiently slow to maintain at least 18 hours efficacy. Efficacy (at least for platelet inhibition) suggested, the question therefore becomes which is the safest agent?

There would appear to be no advantage to combining aspirin with a COX 1 NSAID. This would also address the polypharmacy issue, wherein 1-14 medications (median 6.5) were ingested. If an NSAID is required, regimen simplification suggests that a COX1 agent replace aspirin. Use of a combination product (i.e., Arthrotec) has several advantages over other COX 1 NSAIDs in the at risk population. It also represents a simpler regimen than taking misoprostol three times a day and waiting 20 minutes to subsequently take an NSAID or aspirin dose.

Lack of efficacy of aspirin on collagen and arachidonic acid-induced platelet aggregation and inadequate response in $14 \%$ of aspirin-treated individuals is bothersome, but routinely observed $(4,5,28$, $30)$. Absence of aspirin dose response in the current study mirrors previous reports $(28,31)$. Is aspirin good enough? An excellent, but moot question. At present, no agent has proven more efficacious than aspirin (32).

\section{CONCLUSION}

If NSAIDs are equivalent in efficacy to aspirin, one could conclude that therapeutic regimens can be simplified in those individuals who require an 
NSAID for other problems. If those patients are in a high risk (for ulcer) group, then use of a COX1 active agent with gastroprotection (i.e., Arthrotec) would appear to be a safe alternative to COX 1 active agent use. High (ulcer) risk patients, without other indications, should also probably receive an agent other than aspirin, given aspirin's gastrointestinal toxicity $(2,8,9)$.

As this is an uncontrolled study, results must be considered preliminary. Hopefully this analysis will stimulate the double blinded, controlled studies required not only to assess the platelet function effects but also to assess efficacy in blocking clinical events, both cardiovascular and gastrointestinal.

\section{Acknowledgements}

Appreciation is expressed to Mark Helbling II for logistical support in pursuit of this project.

\section{SUMMARY}

This study was conducted to assess the feasibility of COX1 NSAID substitution for aspirin for preventative therapy related to circulating anticoagulants, as manifest by inhibition of platelet aggregation. There was no difference in platelet aggregation inhibition between aspirin, naproxen, ketoprofen or diclofenac and misoprostol (in combination in the form of Arthrotec).

As COX1 NSAIDs appear equivalent in platelet inhibition efficacy to aspirin, therapeutic regimens can be simplified in those individuals who require an NSAID for other problems. Further, despite its short serum halflife, Arthrotec appears as effective as an antiplatelet agent. Controlled, double blind studies of efficacy in blocking clinical events (both cardiovascular and gastrointestinal) are recommended.

Key words - Circulating anticoagulant, platelet function, nonsteroidal antiinflammatory agents, aspirin.

Parole chiave - Anticoagulante circolante, funzione piastrinica, farmaci anti-infiammatori non steroidei, aspirina

\section{REFERENCES}

1. Dyken ML, Barnett HJ, Easton JD, Fields WS, Fuster V, et al. Low dose aspirin and stroke. Stroke 1992; 23: 1395-9.

2. The SALT Collaborative Group. Swedish aspirin low dose trial (SALT) of $75 \mathrm{mg}$ aspirin as a secondary prophylaxis after cerebrovascular ischaemic events. Lancet 1991; 338: 1345-9.

3. Garcia Rodriguez LA, Varas C, Patrono C. Differential effects of aspirin and non-aspirin nonsteroidal antiinflammatory drugs in the primary prevention of myocardial infarction in postmenopausal women. Epidemiology 2000; 11: 383-7.

4. Kawasaki T, Ozeki Y, Igawa T, Kambayashi J I. Increased platelet sensitivity to collagen in individuals resistant to low dose aspirin. Stroke 2000; 31: 591-5.

5. Patrono C, Coller B, Dalen JE, Fuster V, Gent M, Harker LA, et al. Platelet active drugs: The relationships among dose, effectiveness and side effects. Chest 1998; 114: 470S-88S.

6. Ray WA, Stein CM, Hall K, Daugherty JR, Griffin MR. Nonsteroidal anti inflammatory drugs and risk of serious coronary heart disease: An observational cohort study. Lancet 2002; 359: 118-23.

7. Catella Lawson F, Reilly MP, Kapoor SC, Cucchiara AJ, DeMarco S, Tournier B, et al. Cyclooxygenase inhibitors and the antiplatelet effects of aspirin. N Engl i Med 2001; 345: 1809-17.
8. Cryer B, Feldman M. Effects of very low daily, long term aspirin therapy on gastric, duodenal, and rectal prostaglandin levels and on mucosal injury in healthy humans. Gastroenterology 1999; 117: 17-25.

9. Wil J, Colin Jones D, Langman M, Lawson D, Logan R, Murphy M, et al. Prophylactic aspirin and risk of peptic ulcer bleeding. Brit Med J 1995; 310: 827-30.

10. Watson DJ, Rhodes T, Cai B, Guess HA. Lower risk of thromboembolic cardiovascular events with naproxen among patients with rheumatoid arthritis. Arch Intern Med 2002; 162: 1105-10.

11. Rahme E, Pilote L, LeLorier J. Association between naproxen use and protection against myocardial infarction. Arch Intern Med 2002; 162: 1111-5.

12. Lauer MS. Aspirin for primary prevention of coronary events. N Engl J med 2002; 346: 1468-74.

13. Brochier ML. Evaluation of flurbiprofen for prevention of reinfarction and reocclusion after successful thrombolysis or angioplasty in acute myocardial infarction. Europ Heart J 1993; 14: 951-7.

14. Gum PA, Kottke Marchant K, Poggio ED. Profile and prevalence of aspirin resistance among patients with cardiovascular disease. Amer J Cardiol 2001; 88: 2305.

15. McKenna F. Diclofenac/Misoprostol: The European clinical experience. J Rheumatol 1998; 25 Suppl 51: 2130.

16. Gryfe CI, Gryfe BM. Drug therapy of the aged: The problem of compliance and the roles of physicians and 
pharmacists. J Amer Geriatrics Soc 1984; 32: 301-7.

17. Bedell SE, Jabbour S, Goldberg R, Glaser H, Gobble $S$, et al. Discrepancies in the use of medications: Their extent and predictors in an outpatient practice. Arch Intern Med 2000; 160: 2129-34.

18. Simon LS, Smolen JS, Abramson SB, Appel G, Bombardier C, Brater DC, et al. Controversies in COX 2 selective inhibition. J Rheumatol 2002; 29: 1501-10.

19. Rothschild BM. Non-steroidal anti inflammatory drugs and risk of serious coronary heart disease. Lancet 2002; 360: 89-90.

20. Hudson M, Baron M, Rahme E, Pilote L. Anti inflammatory drugs are associated with a decreased risk of recurrent acute myocardial infarction in patients on aspirin. Arthritis Rheum 2002; 46: S617.

21. Van Solingen RM, Rosenstein ED, Mihailescu G, Drejka ML, Kalia A, et al. Comparison of the effects of ketoprofen on platelet function in the presence and absence of aspirin. Amer i Med 2001; 111: 285-9.

22. Griffin MR, Ray, WA, Schaffner W. Nonsteroidal antiinflammatory drug use and death from peptic ulcer in elderly persons. Ann Intern Med 1988; 109: 359-63.

23. Fries JR, Williams CA, Bloch DA, Michel BA. Nonsteroidal anti-inflammatory drug associated gastropathy: Incidence and risk factor models. Amer J Med 1991; 91: 213-22.

24. Silverstein FE, Graham DY, Senior JR, Davies HW, Struthers BJ, Bittman RM, et al. Misoprostol reduces serious gastrointestinal complications in patients with rheumatoid arthritis receiving nonsteroidal anti-inflammatory drugs: a randomized, double blind, place- bo controlled trial. Ann Intern Med 1995; 123: 241-9.

25. Ginsburg KS, Liang MH, Newcomer L. Anticardiolipin antibodies and risk for ischemic stroke and venous thrombosis. Ann Intern Med 1992; 117: 997-1002.

26. Schoenfeld Y, Meroin PL. The beta-2-glycoprotein I and antiphospholipid antibodies. Clin Exp Rheumatol 1992; 10: 205-9.

27. Cibere J, Sibley JT, Haga M. Rheumatologistsl adherence to guidelines for misoprostol use in patients at high risk for nonsteroidal antiinflammatory drug gastropathy. J Rheumatol 2002; 29: 339-46.

28. Helgason CM, Tortorice KL, Winkler SR, Penny DW, Schuler ii, McClelland TJ, Brace LD. Aspirin response and failure in cerebral infarction. Stroke 1993; 24: 345-50.

29. Nishihara K, Furst DF. Aspirin and other nonsteroidal antiinflammatory drugs. In (Koopman WJ, editor). Arthritis and Allied Conditions. Baltimore: Williams \& Williams 1997: 611-54.

30. Flower RJ, Moncada S, Vane JR. Analgesics: Anitpyretics and anti inflammatory agents. In (Goodman AG, Goodman LS, Gilman A, editors). The Pharmacological Basis of Therapeutics. New York: Macmillan Publishing 1980: 694.

31. The Dutch TIA Trial Study Group. A comparison of two doses of aspirin ( $30 \mathrm{mg}$ vs. $283 \mathrm{mg}$ a day) in patients after a transient ischemic attack or minor ischemic stroke. N Engl J Med 1991; 325: 1261-6.

32. Newby LK, Califf RM, White HD. The failure of orally administered glycoprotein IIb/IIIa inhibitors to prevent recurrent cardiac events. Amer J Med 2002; 112: 647-58. 